\title{
An interesting case of fronto cutaneous fistula
}

\section{Gurumani Sriraman*, Raj Prakash Dharmapuri Yaadhava Krishnan, Roopak Visakan Raja}

Department of Otorhinolaryngology, Shri Satya Sai Medical College and Research Institute, Thiruporur, Chennai, Tamil Nadu, India

Received: 08 May 2017

Revised: 10 June 2017

Accepted: 14 June 2017

\section{*Correspondence:}

Dr. Gurumani Sriraman,

E-mail: srigurumani@ rocketmail.com

Copyright: (c) the author(s), publisher and licensee Medip Academy. This is an open-access article distributed under the terms of the Creative Commons Attribution Non-Commercial License, which permits unrestricted non-commercial use, distribution, and reproduction in any medium, provided the original work is properly cited.

\begin{abstract}
Fronto cutaneous fistula is a very rare entity which usually occurs as a complication of long standing frontal sinusitis leading to frontal bone osteomyelitis. Its incidence has decreased due to the wide spread use of antibiotics. In this era we would like to report a rare case of fronto cutaneous fistula secondary to sino nasal malignancy. A 65 year old female presented to the ENT out patient service of our Hospital with complaints of discharging sinus in the left forehead for 2 months. There was blurring of vision in the right eye for one year .She was a known diabetic. General examination showed that there was a mild swelling around the right orbit and the right eye was significantly proptosed. Routine ENT examination revealed that there was a suspicious nasal mass in the right nasal cavity on anterior rhinoscopy later confirmed by diagnostic nasal endoscopy. Ear and Throat were normal. Neurology opinion was obtained which stated that the findings were suggestive of an intracranial Space occupying lesion extending into the right orbit. Urgent CT was ordered. Routine laboratory investigations were normal except the ESR value which was $60 \mathrm{~mm}$ at end of 1 hour. CT scan showed a sinonasal mass existed centered over the right nasal cavity extending into the surrounding sinuses, near complete erosion of lamina papyracea with extension into right orbit. Biopsy of was done. The biopsy showed squamous cell carcinoma with poorly to moderately differentiated cells. However as the patient was not willing for surgery, hence chemoradiation was advised.
\end{abstract}

Keywords: Frontal sinusitis, Frontal osteomyelitis, Sinonasal malignancy, Fronto - cutaneous fistula

\section{INTRODUCTION}

Fronto cutaneous fistula is a very rare entity which usually occurs as a complication of long standing frontal sinusitis leading to frontal bone osteomyelitis. ${ }^{1}$ Its incidence has decreased due to the wide spread use of antibiotics. ${ }^{2,3}$ In this era we would like to report a rare case of fronto cutaneous fistula secondary to sino nasal malignancy.

\section{CASE REPORT}

A 65 year old female presented to the ENT out patient service of our Hospital with complaints of discharging sinus in the left forehead for 2 months. She reported that the sinus initially developed as a small swelling which gradually increased in size 4 months ago and subsequently burst to form a sinus (Figure 1). There was blurring of vision in the right eye for the past one year which was attributed to senile cataract as she gave history of cataract surgery in the left eye 6 years back.

She was a known diabetic on regular treatment for two years. She claims to have taken some indigenous ayurvedic pill for diabetes for a period of 2 weeks which she later stopped. There was no significant and relevant family history.

General examination showed that there was a mild swelling around the right orbit and the right eye was 
significantly proptosed with difficulty in eye movement which the patient failed to complain, otherwise the patient was normal. Vitals were stable and systemic examination revealed no abnormality.

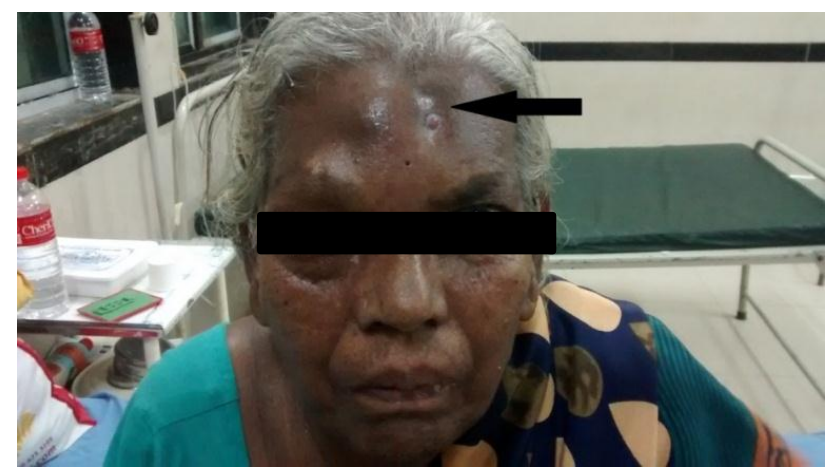

Figure 1: Showing fronto cutaneous fistula on the left forehead with eccentric proptosis of the right eye.

Routine ENT examination revealed that there was a suspicious nasal mass in the right nasal cavity on anterior rhinoscopy. Ear and throat were normal.

Diagnostic nasal endoscopy was attempted to further explore the asymptomatic nasal mass. A non-friable reddish polypoidal mass almost blocking the entire right nasal cavity was visualized.
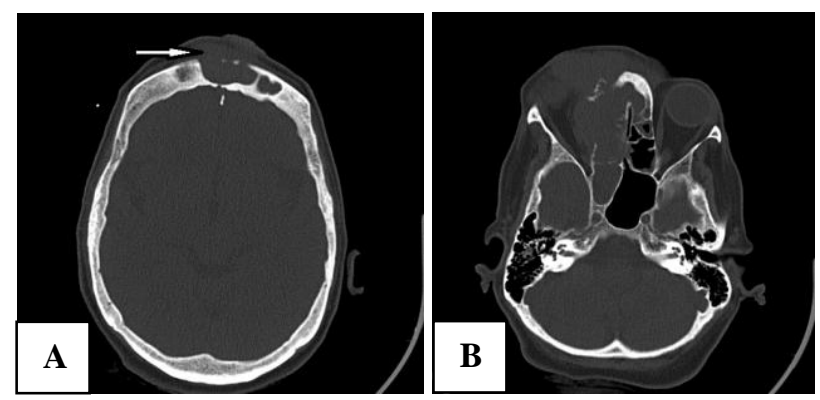

Figure 2 (A and B): Showing extension of the lesion over the ethmoids extending into the Orbit, sphenoid sinus and the frontal sinus.

To rule out any orbital pathology and intracranial involvement, ophthalmology and neurology opinions were obtained. The ophthalmologist opinion revealed that that there was mild eccentric proptosis of the right eye down and out with restricted movements in the medial and upper aspects with grade 1 chemosis and Senile immature cataract with vision of $1.5 / 60$. Bilateral pupils and fundus examination was normal.

Neurology opinion stated that the findings were suggestive of an intracranial space occupying lesion extending into the right orbit as well as to the right superior orbital fissure with possible damage to the 2, 3, 4, 6 cranial nerves. An urgent CT scan of brain was ordered.
The basic battery of routine laboratory investigations and tests were normal except the ESR value which was 60 $\mathrm{mm}$ at the end of one hour. Chest $\mathrm{X}$ ray and ECG were normal.
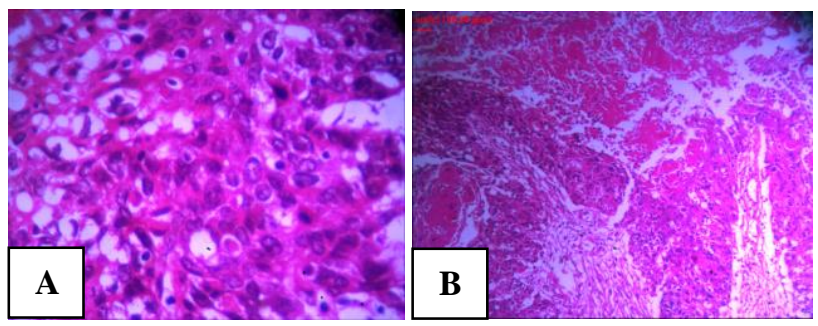

Figure 3: (A) Malignant cells with mitosis, (B) Necrosis stroma infiltration.

CT scan showed that a sinonasal mass existed centered over the right nasal cavity extending into the surrounding sinuses. Near complete erosion of lamina papyracea was observed with lobulated mass extending into right orbit with mass effect on orbit and its structures. Bony erosion of cribriform plate was also noted with extension into anterior cranial fossa (Figure 2). Multiple intra parotid lymph nodes were noted on both sides with lymph nodes also noted in the right posterior triangle of the neck.

Based on the history of long standing diabetes and clinical examination of the patient along with CT reports the following conditions were suspected.

1. Right nasal mucormycosis with frontal extension. ${ }^{4}$

2. Sinonasal polyp with persistent frontal sinusitis leading to frontal osteomyelitis with fronto cutaneous fistula.

3. Sinonasal maliganacy.

To rule out other possibilities and to confirm the diagnosis a biopsy of the sinonasal mass along with culture and gram stain of the frontal sinus discharge was done.

The frontal sinus discharge was negative for any organism and the biopsy showed that the mass was squamous cell carcinoma with poorly to moderately differentiated cells (Figure 3).

With the help of the CT report the malignancy was staged as IV A and the patient was planned for endoscopic resection. ${ }^{5}$ However as the patient was not willing for surgery, chemoradiation was advised. ${ }^{6}$

Primary malignancy arising in the sinonasal cavity is relatively rare accounting for only 3 per cent of all head and neck tumors. ${ }^{7}$ The tumours are mostly epithelial tumours including squamous cell carcinoma and melanoma and very rarely non squamous cell epithelial tumours. Metastasis, osseous lesions, soft tissue sarcomas and lymphoproliferative disease can also involve the sinonasal cavity. ${ }^{8}$ 


\section{CONCLUSION}

Sinonasal malignancies are very rare. Initial early symptoms of sinonasal malignancy are nonspecific and can be mistaken for benign conditions and hence these tumours mostly present at an advanced stage locally. Fronto cutaneous fistula usually occurs secondary to frontal osteomyelitis. Hence we are reporting this case of frontocutaneous fistula which has occurred secondary to a sinonasal malignancy which is a very unique entity. Therefore we must develop a high index of suspicion in patients presenting with frontocutaneous fistula to rule out any other co-existing conditions for prompt and effective treatment of the patient.

Funding: No funding sources Conflict of interest: None declared

Ethical approval: Not required

\section{REFERENCES}

1. Wu VF, Smith TL, Poetker DM. Sinocutaneous fistula secondary to chronic frontal rhinosinusitis: case series and literature review. Ann Otol Rhinol Laryngol. 2008;117(10):759-63.

2. Marshall AH, Jones NS. Osteomyelitis of the frontal bone secondary to frontal sinusitis. J Laryngol Otol. 2000;114(12):944-6.
3. Ali ZS, Deviprasad. Chronic frontal sinusitis presenting with complications. Arch Med Health Sci. 2013;1:163-5.

4. Petrikkos G, Skiada A, Lortholary O, Roilides E, Walsh T, Kontoyiannis DP. Epidemiology and clinical manifestations of mucormycosis. Clin Infect Dis. 2012;54(1):23-34.

5. Nicolai $P$, Battaglia $P$, Bignami M, Bolzoni Villaret $A$, Delù G, Khrais T, et al. Endoscopic surgery for malignant tumors of the sinonasal tract and adjacent skull base: A 10-year experience. Am J Rhinol. 2008;22(3):308-16.

6. Rischin D, Porceddu S, Peters L, Martin J, Corry J, Weih, L. Promising results with chemoradiation in patients with sinonasal undifferentiated carcinoma. Head Neck, 2004;26:435-441.

7. Yuen HY, Kew J, van Hasselt CA, Maxilla and sinuses in imaging in head and neck cancer: a practical approach. London: Greenwich Medical Media, 2003.

8. Resto VA, Deschler DG. Sinonasal malignancies. Otolaryngol Clin North Am. 2004;37:473-87.

Cite this article as: Sriraman G, Krishnan RPDY, Raja RV. An interesting case of fronto cutaneous fistula. Int J Otorhinolaryngol Head Neck Surg 2017;3:761-3. 